\title{
The event-related desynchronization (ERD) correlated to psychometric intelligence in Brazil: a neural efficiency study methodology
}

\author{
Marcela Mansur-Alves*, Sady Antonio dos Santos Filho, Carmen Flores-Mendoza, \\ Carlos Julio Tierra-Criollo
}

\begin{abstract}
The phenomenon of alpha band desynchronization (ERD) has been extensively studied as an electrophysiological correlation of individual intelligence differences. However, in Brazil, there is lack of research regarding the subject. The present study intended to verify the relationship between psychometric intelligence and neural efficiency, using event-related desynchronization, on children with different intellectual levels. Eight clinically healthy male children with an average age of 8.75 years, from the city of Belo Horizonte, participated in the study, divided into one high IQ group and one average IQ group. The children had their intelligence evaluated by psychometric tests and EEGs were collected in two different moments - during rest and while performing cognitive tasks. The results showed that the more intelligent children presented lower percentages of ERD when compared to the average IQ group, for frontal, parietal and temporal regions, though the differences between the groups did not achieve statistical significance. To sum up, this study presented a preliminary evidence of a methodology for neural efficiency studies using event-related desynchronization correlated to the psychometric intelligence tests used in Brazilian children. However, new studies are required to verify the generality of this methodology and the findings of the present study.
\end{abstract}

Keywords Intelligence, Neural efficiency, Electroencephalography, Child.

\section{A dessincronização relacionada a evento (DRE) correlacionada à inteligência psicométrica no Brasil: uma metodologia para estudo da eficiência neuronal}

Resumo O fenômeno da dessincronização relacionada a evento (DRE) da banda alfa tem sido extensivamente estudado como um correlato eletrofisiológico das diferenças individuais em inteligência. Contudo, no Brasil, há escassez de pesquisas relativas ao tema. O presente estudo objetiva verificar a relação entre inteligência psicométrica e eficiência neuronal, por meio da metodologia de dessincronização relacionada a evento, em crianças com diferentes níveis intelectuais. Participaram do estudo oito crianças da cidade de Belo Horizonte, do sexo masculino, com idade média de 8,75 anos, clinicamente saudáveis divididas em grupo de alto QI e médio QI. As crianças tiveram sua inteligência avaliada por meio de testes psicométricos e o EEG coletado em dois momentos distintos - durante o repouso e durante a realização de tarefas cognitivas. Os resultados mostraram que as crianças de maior inteligência apresentaram menores porcentagens de DRE quando comparadas as de QI médio, para as regiões frontal, parietal e temporal, embora as diferenças entre os grupos não tenham alcançado significância estatística. Para concluir, o presente estudo apresentou evidências iniciais de uma metodologia para estudos da eficiência neuronal, utilizando a dessincronização relacionada a evento, correlacionada a testes de inteligência psicométrica em crianças brasileiras. Entretanto, novos estudos são necessários para verificar a generalidade dessa metodologia e dos achados do presente estudo.

Palavras-chave Inteligência, Eficiência neuronal, Eletroencefalografia, Criança. 


\section{Introduction}

Human intelligence is one of the most studied aspects of psychological functioning by psychological science since its origin (Lubinski, 2004). Intelligence may be understood, generally, as the capacity to solve problems, think abstractly, learn with experience and adapt to the environment (Neisser et al., 1996). Even though there may still be discordance about the specific dimensions and the structural organization of intelligence, regardless of the theoretical reference used, most researchers in the area recognize the importance of intelligence for individual success in several aspects of life (Strenze, 2007). From now on, the word "intelligence" will be used to refer to the individual's performance on tests of psychometric intelligence.

One of the ways to study intelligence is to approach it by its biological aspects (Andrés-Puyeo, 2006). It can be assumed that the first studies using a biological perspective of intelligence date from over two centuries ago, when various attempts of locating superior cognitive functions in the brain were performed (Jung and Haier, 2007). However, since the discovery of the human electroencephalogram (EEG), in 1929, a significant amount of studies has sought to verify the relationship between cerebral electrical activity and psychometric intelligence (Duffy et al., 1999). The EEG parameters used in association to intelligence vary greatly from one study to another. However, it may be nevertheless observed that there is a recurrence of studies which aims at finding a correlation between different EEG band powers, especially alpha (8 to $13 \mathrm{~Hz}$ ) and theta bands (4 to $8 \mathrm{~Hz}$ ), and cognitive and memory processes (Klimesch, 1999). Basically, the methodology of such studies is to compare EEG band power during rest or a reference state with that of a period of cognitive activity use. When power increases from rest to the cognitive test, it is designated event-related synchronization (ERS), while a decrease indicates event-related desynchronization (ERD). Physiologically, the magnitude of desynchronization reflects the amount of neural populations involved in performing a specific activity at a certain moment, though there are variations of neural response for all frequency bands (Klimesch, 1999; Pfurtscheller et al., 1996).

The phenomenon of alpha band desynchronization (ERD) has been extensively studied as an electrophysiological correlation of individual diferences in intelligence (Neubauer and Fink, 2009). It is assumed that the ERD of alpha band activity reflects an increased excitability level of neurons in the involved cortical areas, which may be related, for instance, to an enhanced of energy consumption to solve a cognitive problem (Klimesch, 1999). In general, research in the area points to an inverse relationship between psychometric intelligence and cortical activation while performing elementary cognitive tasks, or working memory and problem solving tasks. In this sense, highly intelligent individuals would present significantly lower amount of desynchronization (i.e, less cortical activation or less energy consumption) in alpha bands when compared to those with lower IQs (Grabner et al., 2004; Jausovec, 1996; Klimesch et al., 1997). These results indicate that more intelligent individuals need to use fewer resources (energy consumption) to deal with required cognitive demands, that is, they have a greater neural efficiency (Haier et al., 1992). However, the literature highlights the presence of moderator variables of the relationship between intelligence and cortical activation, such as gender, task complexity and cerebral topography (Neubauer and Fink, 2009). Though the neural efficiency phenomenon has been systematically studied in adult samples from European countries and the United States, such studies are almost inexistent in children, especially in Brazil.

In this sense, the present study aims to verify the applicability of event-related desynchronization methodology to study the relationship between psychometric intelligence and neural efficiency, in Brazilian children with different levels of intelligence, considering that there is no evidence of such applicability for this population. Moreover, even considering other countries, the evidence of the ERD phenomenon for children is contradictory and the results came from the ERD methodology can be, sometimes, confusing. In addition, the cognitive tasks proposed herein have a greater cognitive demand than those mentioned in the literature for this area, especially in studies with children.

\section{Materials and Methods}

\section{Participants}

For the present study, an evaluation was initially performed on 124 children from a public federal school of the city of Belo Horizonte, in the fourth and fifth years of the second school cycle, $54 \%$ male, with an average age of 9.19 years and a standard deviation of 0.667 . To participate in the present research, the evaluated children should meet the following inclusion criteria:

- be in the high (more than 120 points) average (between 95 to 110) or low (between 70 to 85) IQ ranges in the three intelligence tests applied

- absence of physical deficiency (auditory or visual) 
- absence of neurological and psychiatric problems in the individual or near relatives (such as autism, mental deficiency, bipolar disorder, attention deficit disorder/hyperactivity, depression, and others)

- male sex, selecting children of only one sex for intervention, eliminating cognitive, motivational and personality differences related to this variable, which are constantly shown in the literature (Halpern, 1997).

Based on the criteria defined above, 27 boys (seven low IQ, fourteen average IQ and six high IQ) were selected. However, only nine boys (three high IQ, one low IQ and 5 average IQ) effectively participated in the research since parental consent for the remaining children's participation in the study was not granted. The low IQ child was not included in data analysis. The average age of the boys was 8.75 years, with a standard deviation of 0.44 , and all were in the fourth year of the second cycle.

\section{Procedures}

1. For the evaluation of child health, a questionnaire was sent to the parents based on the Brazilian version of the Schedule for Affective Disorders and Schizophrenia for School Aged Children - K-SADS (Ambrosini, 2000), containing items regarding mental diseases present in children and first degree relatives. In addition, the medical histories of the children kept by the school Health Service were consulted by the professionals responsible for the study.

2. Raven's Progressive Matrices Test - General Scale, Centro Editor de Psicologia Aplicada (2001): is a measure of non-verbal intelligence, which more specifically evaluates the "g" factor (construct proposed by Spearman), to reduce cultural and varied knowledge contamination of those who were tested. It is the best know e most used measure of psychometric intelligence. The Raven Progressive Matrices (of which there are several versions) are made up of a series of diagrams or designs with a part missing. Those taking the tests are expected to select the correct part to complete the designs from a number of options printed beneath.

3. Non-verbal Child Reasoning Test - NVCRT (Pasquali, 2005): is a Brazilian instrument which was constructed based on Raven's Progressive Matrices, given the vast use the latter has. That way, therefore, it also intends to evaluate general intelligence thought a series of diagrams with missing part. Its application is recommended for children aging from seven to twelve years.

4. Wechsler Intelligence Scale for Children Third Edition (Wechsler, 2002): WISC-II is an instrument applied individually, to evaluate the intellectual capacity of children between 6 and $161 / 2$ years of age. It is composed of various subtests, each measuring a different aspect of intelligence and is used to verify the cognitive performance of the subjects in qualitative and quantitative terms. This scale proposes problems that permit an appreciation of the capacity of the subjects with respect to memory, attention, action planning, spatial orientation and other aspects connected to mental functioning. It is composed of two types of evaluation: that of cognitive performance as related to the verbal aspect, and that of cognitive performance as related to the nonverbal aspect.

5. Informatized Tasks of Working Memory (WM): two WM tasks (Grammatical Alphabet and Numerical Order) were used for cognitive evaluation during EEG data collection. The first consists of the presentation of a series of words, whose first letters the child must remember and type in alphabetical order (for instance: MAU, BAR and $\mathrm{CEU}=\mathrm{B}, \mathrm{C}, \mathrm{M}$ ). The number of words presented increases throughout the tests. The second task consists of performing simple addition mathematical operations (such as $1+1=$ ? and $4+3=$ ?), while memorizing their results, which must be put in ascending order. The performed operations always include numbers which vary from zero to nine. The number of mathematical operations increases throughout the tests. For both tasks, a fixation point is shown on a screen $1.5 \mathrm{~s}$ before the appearance of the test. The space between each test is $500 \mathrm{~ms}$.

6. Digital Electroencephalograph: a biological signal amplifier (BrainNET BNT-36) was used, with high-pass and low-pass filters for $0.1 \mathrm{~Hz}$ and $100 \mathrm{~Hz}$, respectively, a $60 \mathrm{~Hz}$ notch filter and a $600 \mathrm{~Hz}$ sampling frequency. Also, an EEG cap was used, with 20 pre-arranged electrodes (circumference size 54 to $58 \mathrm{~cm}$ ), CAMSOSAA20 model. All EEG collections occurred in the UFMG Biomedical Engineering Laboratory, in an acoustically isolated cabin. There, the subjects were comfortably seated in a chair with armrests to minimize muscular artifacts. The sessions lasted an average of 
1 hour and 15 minutes. Electrode placement on the scalp was performed using an appropriately placed cap, with conductive and adhesive gel, in accordance with the 10-20 international system, with bi-auricular reference and ground on the forehead. The EEG was collected in the following way: 1) awake, with the subject resting, eyes open, during 3 minutes, with orders to try not to blink, swallow saliva or move in an exaggerated form; 2) awake, during cognitive activity. At this phase, the child performed reduced versions of the working memory tasks (Numerical Order and Grammatical Alphabet) presented in the computer in the collection room. The child was asked to avoid, as best as possible, moving. This phase lasted an average of 30 minutes and was supervised by a person located in the collection cabin, along with the child, to press the trigger button which marked the moment when the child performed the cognitive activity, synchronizing it to the computer which collected EEG signals.

The project was approved by the Universidade Federal de Minas Gerais' Ethics Committee, recognized by the Research Ethics National Commission (Comissão Nacional de Ética em Pesquisa - CONEP), in November, 2009.

\section{Data analysis}

The low IQ group was not included, since it was composed of only one child, being statistically impossible to calculate central tendency measures of only one subject. The EEG signals of the frontal, temporal and parietal areas were used since they were the most directly involved in the complex cognitive processes (Gray and Thompson, 2004). Since the presence of alpha waves is recurrent in the literature when dealing with the association of cerebral functioning to human intelligence (Klimesch, 1999), the result analysis herein focuses, especially, on electrophysiological activity of alpha waves. The signals were divided in epochs of approximately 15 seconds (EEG epochs between the first and last trigger signal). The average value of each epoch was removed and, subsequently, an algorithm was applied for automatic rejection of epochs presenting strong artifacts (Tierra-Criollo, 2001). For this, a 15 seconds signal epoch, considered free of artifacts, was selected for the reference standard deviation $(\sigma)$ estimate. Thus, the epochs in which more than $5 \%$ of the continuous samples, or totaling more than $10 \%$ of the samples, exceeded the $3 \sigma$ limit $(99.74 \%$ of the samples assuming Gaussianity), were rejected. A
PSD (Power Spectral Density) was estimated, using the epochs without strong artifacts. Power spectral density function (PSD) shows the strength of the variations (energy) as a function of frequency. In other words, it shows at which frequencies variations are strong and at which frequencies variations are weak. PSD can be defined as the Fourier transform of the autocorrelation function of a signal $x[n]$, which is expressed by (Marple, 1987; Shiavi, 1999):

$$
P_{x x}(f)=\lim _{N \rightarrow \infty} E\left\{\frac{1}{(2 N+1)}\left|\sum_{n=-N}^{N} x[n] \exp (-j 2 \pi f n T)\right|^{2}\right\}
$$

where $E[\bullet]$ refers to the expected value, $N$, the number of samples and $T=1 / f s$, being $f_{s}$ the sampling frequency.

Ignoring the operation of expectancy and assuming that the signal $x[n]$ has finite length of $N$ samples $\{x[n]$, $n=0,1, \ldots, N-1\}$, then the discrete spectrum can be estimated by the periodogram original unmodified (Marple, 1987):

$$
\begin{aligned}
\hat{P}_{x x}(f)= & \hat{P}_{x x}\left(\frac{m}{N T}\right)= \\
& \frac{T}{N}\left|\sum_{n=0}^{N-1} x[n] \exp (-j 2 \pi m n / L)\right|^{2}=\frac{T}{N}|X[m]|^{2}
\end{aligned}
$$

where $m=0,1, \ldots, N-1$ and $X[m]$ is the $m$-th coefficient of the Discrete Fourier Transform (DFT), corresponding to frequency $f=m / N T$. Assuming that $N$ is even, i.e., $\hat{P}_{x x}\left(f_{m}\right)=\hat{P}_{x x}\left(f_{L-m}\right)$, the DFT coefficients are symmetric around $N / 2$.

The periodogram of Bartlett (Marple, 1987) can be used to estimate the PSD. It consists in to segment the signal $x[n]$ in $M$ windows of $N$ samples synchronized with the repetition of the task. Then the PSD can be obtained by:

$\tilde{P}_{x x}(f)=\frac{1}{M} \sum_{i=1}^{M} \hat{P}_{x x}(f)_{i}$

where

$$
\hat{P}_{x x}(f)_{i}=\frac{T}{N}\left|X_{i}[m]\right|^{2}
$$

From the PSD estimated, it was possible to obtain power in the alpha band ( 8 to $13 \mathrm{~Hz}$ ), from the calculation of the area below the PSD curve (Marple, 1987). The normalization of the values of the PSD was performed, based on the total power in the range of 5 to $45 \mathrm{~Hz}$. This band was chosen by taking in the tracks of alpha and beta rhythms, of fundamental importance in the study. The delta band (2 to $4 \mathrm{~Hz})$ was removed from the calculation, because it can contain movement and electrooculagram artifacts. The percentage of synchronization/desynchronization in the alpha band was calculated in the following way: 
$\left[\frac{(\text { power at rest }- \text { power during cognitive activity })}{\text { power at rest }}\right] \cdot 100$

for the $F$ derivations (power average on frontal electrodes), $P$ (power average on parietal electrodes) and $T$ (power average on temporal electrodes) for each cognitive task (numerical and alphabetical). Negative values indicate synchronization in the alpha rhythm and positive values indicate desynchronization in alpha (Klimesch, 1999). Table 1 presents the relationship between ERD/ERS, power and cortical activity (Pfurtscheller et al., 1996).

The Spearman correlation was used for the calculation of the association between ERD percentage and child intelligence level. For group comparison analyses (high and average IQ), the Mann-Whitney $\mathrm{U}$ test was used, due to sample size.

\section{Results}

Table 2 shows the characterization of the sample submitted to the EEG and child performance in the WM cognitive tasks during which EEG was collected.

In general, the Numerical Order task, in which the child performed mathematical operations, may be considered more difficult than the Alphabet task (language) - average proportion of correct answers for the first (0.66) was lower than for the latter (0.79). This observation is confirmed when also compared to the average proportion of correct answers between IQ groups. For the numerical order task, the high IQ group obtained a higher correct answer average proportion $(\mathrm{M}=0.86$ of $12, \mathrm{SD}=0.08)$ than the average IQ group $(\mathrm{M}=0.54, \mathrm{SD}=0.13)$, however, these differences are not statistically significant $(p=0.250)$. For the alphabet task, the difference between the correct answer average proportions of the two groups is lower $(\mathrm{M}=0.81$ for the high group and $\mathrm{M}=0.75$ for the average group), once again without a significant difference $(p=0.393)$.

Regarding synchronization/desynchronization percentage, Table 3 and Figure 1 show that the high IQ children presented lower ERD percentages for all regions (parietal, frontal and temporal). The greatest differences in ERD between high IQ and average IQ children were found for the frontal region, both for the cognitive numerical task and for the alphabet task (verbal). It can also be observed that the greatest ERD differences between the groups occurred in the numerical task. To verify if ERD averages were different for the two IQ groups, a Mann-Whitney $\mathrm{U}$ test was performed for the independent samples, since the dependent variable (ERD) does not have a normal distribution and sample size is small. One child of the average IQ group was removed from the analyses, since he presented extreme (outlier) values in all ERD measurements. The Mann-Whitney test did not show significant differences between the groups in ERD percentages for the numerical task for any of the cerebral regions (frontal $\mathrm{U}=2.000$, $p=0.157$; parietal $\mathrm{U}=4.000, p=0.480$; temporal $\mathrm{U}=4.000, p=0.480)$. A similar result was found for the alphabet/verbal task in all regions (frontal $\mathrm{U}=5.000, p=0.724$; parietal $\mathrm{U}=6.000, p=1.000$; temporal $\mathrm{U}=5.000, p=0.724$ ).

When a correlation is made between child intelligence level and ERD percentage, negative correlations are obtained, though without statistical significance, for the alphabet task in the parietal $(\rho=-0.36, p=0.939)$, frontal $(\rho=-0.14, p=0.758)$ and temporal $(\rho=-0.07, p=0.878)$ regions. Regarding

Table 1. Representation of the relationship between ERD, power and neural activity.

\begin{tabular}{cccc}
\hline Values & ERD/ERS & Power & Neural activity \\
\hline Positive $(+)$ & Desynchronization & Decrease & Greater \\
Negative $(-)$ & Synchronization & Increase & Lower \\
\hline
\end{tabular}

Table 2. Sample and performance characteristics (correct answer proportion) in cognitive tasks.

\begin{tabular}{clccc}
\hline Subject & \multicolumn{1}{c}{ Age } & IQ & Numerical order task & Alphabet task \\
\hline S1 & 8 years and 9 months & 127 (high) & 0.92 & 0.78 \\
S2 & 9 years and 9 months & 127 (high) & 0.92 & 0.75 \\
S3 & 9 years and 3 months & 121 (high) & 0.50 & 0.78 \\
S4 & 8 years and 9 months & 97 (average) & 0.45 & 0.59 \\
S5 & 9 years and 1 month & 96 (average) & 0.75 & 0.56 \\
S6 & 9 years and 5 months & 107 (average) & 0.42 \\
S7 & 9 years and 6 months & 101 (average) & 0.78 \\
S8 & 9 years and 3 months & 105 (average) & & 0.89 \\
\hline
\end{tabular}


Table 3. Mean and standard deviation of ERS/ERD percentage by IQ group.

\begin{tabular}{lrrrrr}
\hline \multirow{2}{*}{\multicolumn{1}{c}{ ERS/ERD }} & \multicolumn{2}{c}{ High IQ } & & \multicolumn{2}{c}{ Medium IQ } \\
\cline { 2 - 3 } \cline { 6 - 6 } & M & \multicolumn{1}{c}{ SD } & & M & SD \\
\hline Parietal-numerical & 20.000 & 16.65 & & 28.508 & 12.88 \\
Parietal-verbal & 26.222 & 9.70 & & 26.778 & 15.83 \\
Frontal-numerical & 21.303 & 7.30 & & 33.763 & 11.84 \\
Frontal-verbal & 24.234 & 9.98 & & 25.877 & 20.06 \\
Temporal-numerical & 31.372 & 18.32 & & 40.019 & 22.76 \\
Temporal-verbal & 36.175 & 13.98 & & 37.210 & 23.17 \\
\hline
\end{tabular}

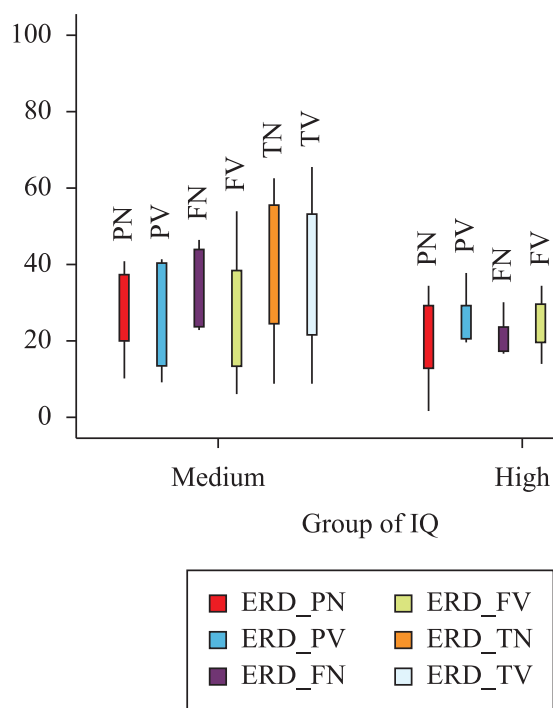

Figure 1. Chart of ERD average percentage and standard deviation for the frontal $(\mathrm{F})$, parietal $(\mathrm{P})$ and temporal $(\mathrm{T})$ regions, for the numerical $(\mathrm{N})$ and alphabet $(\mathrm{V})$ cognitive tasks, by IQ group.

the numerical task, the found correlations were also negative and high for the parietal $(\rho=-0.54, p=0.210)$ and temporal $(\rho=-0.66, p=0.102)$ regions, however, only for the frontal region, the correlations found between IQ and ERD were negative and statistically significant $(\rho=-0.811, p<0.05)$. These results indicate that the higher the intelligence, the lower the ERD percentage, in other words, the greater the neural efficiency.

\section{Discussion}

A widely used electrophysiological parameter used to compare groups of individual of different intellectual levels is event-related desynchronization (ERD) (Neubauer and Fink, 2009). ERD is understood as a measure of the amount of neural populations involved in performing a cognitive activity, which is higher the more neurons are involved in executing that activity (greater cortical activity). Current researches are consistent to point that the greater the intelligence, the lower the alpha band ERD percentage, thus indicating greater neural efficiency in more intelligent people (Doppelmayr et al., 2002, 2005; Grabner et al., 2004; Neubauer et al., 2002).

In the present study, the results found for ERD percentage and its relationship to intelligence support the findings of international studies - higher ERD percentages (greater cortical activity) for average IQ children when compared to ones with high IQs. Besides, the Spearman correlation found between ERD and the intellectual level of the children was negative, indicating that greater intelligence is associated to lower ERD. It is interesting to observe that the greatest ERD differences between high IQ children and average IQ children and, also, the only one with statistical significance, was found for the frontal region, with the average IQ group presenting higher ERD values. It is known that the frontal regions are used when the task requires the development of new strategies, planning and monitoring, being more used the harder the task is considered by the individual, as occurs in working memory tasks (Doppelmayr et al., 2005; Neubauer and Fink, 2009; Pfurtscheller et al., 1996). Working memory tasks demand very much of the individual's cognitive system, requiring a great amount of cerebral energy to solve them effectively, especially for individuals with lower intellectual capacity (Kane and Engle, 2002). The cognitive tasks proposed herein have a greater cognitive demand than those mentioned in the literature for this area (Fink et al., 2005; Grabner et al., 2004; Neubauer and Fink, 2009).

Another interesting result found in the present study was the greater differences between IQ groups for the numerical task. Actually, the only correlation between ERD and intelligence which achieved statistical significance was for the numerical task in the frontal region. Some authors (Neubauer et al., 2002; Fink and Neubauer, 2006) show that subject gender seems to interact with task content and ability mastery evaluated in result determination. Thus, these authors found support for the neural efficiency hypothesis (that is, negative association between intelligence and cerebral activation) for men mainly when they are performing visual-spatial and numerical content tasks, but not for verbal ones. That means that even men with high IQs require greater mental effort to deal with verbal contents that they do not grasp easily. These results match those found herein and those found in studies which have been frequently reporting gender differences in specific cognitive abilities (Halpern, 1997), with men presenting better performance in visual-spatial and numerical tasks 
and women in verbal tasks. However, it would be necessary to include a sample composed of girls to verify the confirmation of this result.

Though the results of this paper add important information to the literature of this area, some final considerations are required. Firstly, the use of a larger sample would be necessary to check if the results found only as a tendency would reach statistical significance. The refusal of children's parents to allow theirs participation in this research was the main responsible for the small sample size. In Brazil, especially in the low educational levels, parents have great difficulty in understanding the purposes of scientific research, particularly when it comes to tests that assess brain function. It would also be interesting to extend the analyses performed to the remaining EEG bands that are related to cognition, such as the theta band. The theta band, especially in the parietal and frontal regions, would be related to attentional processes, which are fundamental for solving new and highly complex problems (Klimesch, 1999). It would also be important to divide the alpha band in two different frequency sub-bands (inferior alpha band, between 7 and $10 \mathrm{~Hz}$, and superior alpha band between 10 and $13 \mathrm{~Hz}$ ), since the literature points to distinct desynchronization patterns for these two sub-bands. For the division of the alpha band in two sub-bands, it is common to use the method known as IAF (Individual Alpha Frequency), which suggests that the band limits be defined individually (Klimesch, 1999). In short, research that uses event-related desynchronization to verify individual differences in intelligence is rare in Brazil.

\section{Conclusion}

The present study aimed to verify the applicability of event-related desynchronization methodology to study the relationship between psychometric intelligence and neural efficiency, in Brazilian children with different levels of intelligence. The main findings of the present study can on the one hand be seen as a partially successful replication of the ERD methodology and of previous findings of other researches in the field. In this study, the phenomenon of ERD was corroborated in Brazilian children of high and medium IQ for reasoning and working memory tasks, which was interpreted as a possible physiological source for the frequently reported individual differences in intelligence between people. This interpretation is somewhat complicated by the shortcomings of the study, which have already been outlined in the discussion.

However, the methodology and some results found herein represent an important step in this area, since the studies of neural efficiency and intelligence in children are practically inexistent. Notwithstanding, new studies are required, since the inclusion of the above suggested modifications would allow the achievement of a richer and more detailed relationship between intelligence and cerebral functioning trough the ERD methodology.

\section{Acknowledgements}

This project was financed by the Coordenação de Aperfeiçoamento de Pessoal de Nível Superior (CAPES), Conselho Nacional de Desenvolvimento Científico e Tecnológico (CNPq) e Fundação de Amparo à Pesquisa do Estado de Minas Gerais (FAPEMIG) - Brazil.

\section{References}

Ambrosini PJ. Historical development and present status of the Schedule for Affective Disorders and Schizophrenia for School-Age Children (K-SADS). Journal of the American Academy of Child and Adolescent Psychiatry. 2000; 39:49-58. http://dx.doi.org/10.1097/00004583-200001000-00016

Andrés-Pueyo A. Modelos Psicométricos da Inteligência. In Flores-Mendoza C, Colom, R, organizadores. Introdução à Psicologia das Diferenças Individuais. Porto Alegre: Artmed; 1996. p. 73-102.

Centro Editor de Psicologia Aplicada - CEPA. Manual das Matrizes Progressivas de Raven - Escala Geral. Séries A, B, C, D e E. 2a ed. Tradução e adaptação de Francisco Campos. Rio de Janeiro: CEPA; 2001.

Doppelmayr M, Klimesch W, Sauseng P, Hödlmoser K, Stadler W, Hanslmayr S. Intelligence related differences in EEG-bandpower. Neuroscience Letters. 2005; 381:309-13. PMid:15896490. http://dx.doi.org/10.1016/j. neulet.2005.02.037

Doppelmayr M, Klimesch W, Stadler W, Pollhuber D, Heine C. EEG alpha power and intelligence. Intelligence. 2002; 30:289-302. http://dx.doi.org/10.1016/ S0160-2896(01)00101-5

Duffy FH, Iyer VG, Surwillo WW. Eletroencefalografia clínica e mapeamento cerebral topográfico: tecnologia e prática. Rio de Janeiro: Revinter; 1999.

Fink A, Grabner RH, Neuper C, Neubauer AC. EEG alpha band dissociation with increasing task demands. Cognitive Brain Research. 2005; 24:252-59. PMid:15993763. http:// dx.doi.org/10.1016/j.cogbrainres.2005.02.002

Fink A, Neubauer AC. EEG alpha oscillations during the performance of verbal creativity tasks: differential effects of sex and verbal intelligence. International Journal of Psychophysiology. 2006; 62:46-53. PMid:16503062. http:// dx.doi.org/10.1016/j.ijpsycho.2006.01.001

Grabner RH, Fink A, Stipacek A, Neuper C, Neubauer AC. Intelligence and working memory systems: evidence of neural efficiency in alpha band ERD. Brain Res Cognitive 
Brain Research. 2004; 24: 212-25. PMid:15183393. http:// dx.doi.org/10.1016/j.cogbrainres.2004.02.010

Gray JR, Thompson P. Neurobiology of intelligence: Science and Ethics. Nature. 2004; 5:471-82. PMid:15152197. http:// dx.doi.org/10.1038/nrn1405

Haier R J, Siegel B, Tang C, Abel L, Buchsbaum MS. Regional glucose metabolic changes after learning a complex visuospatial/motor task: a positron emission tomography study. Brain Research. 1992; 570:134-43. http://dx.doi. org/10.1016/0006-8993(92)90573-R

Halpern D. Sex Differences in Intelligence: Implications for education. American Psychologist. 1997; 52:1091-102. PMid:9329293. http://dx.doi.org/10.1037/0003066X.52.10.1091

Jausovec N. Differences in EEG Alpha activity related to giftedness. Intelligence. 1996; 23:159-73. http://dx.doi. org/10.1016/S0160-2896(96)90001-X

Jung RE, Haier RJ. The Parieto-Frontal Integration Theory (P-FIT) of intelligence: Converging neuroimaging evidence. Behavioral and Brain Sciences. 2007; 30:135-87. PMid:17655784. http://dx.doi.org/10.1017/ S0140525X07001185

Kane MJ, Engle RW. The role of prefrontal cortex in working-memory capacity, executive attention, and general fluid intelligence: an individual differences perspective. Psychonomic Bulletin \& Review. 2002; 9:637-71. http:// dx.doi.org/10.3758/BF03196323

Klimesch W, Doppelmayr M, Pachinger T, Russegger H. Event-related desynchronization in the alpha band and the processing of semantic information. Cognitive Brain Research. 1997; 6:83-94. http://dx.doi.org/10.1016/S09266410(97)00018-9

Klimesch W. EEG alpha and theta oscillations reflect cognitive and memory performance: a review and analysis. Brain Research Reviews. 1999; 29:169-95. http://dx.doi. org/10.1016/S0165-0173(98)00056-3

Lubinski D. Introduction to the special section on cognitive abilities: 100 years after Spearman's (1904) “General
Intelligence, Objectively Determined and Measured". Journal of Personality and Social Psychology. 2004; 86:96-111. PMid:14717630. http://dx.doi.org/10.1037/0022-3514.86.1.96

Marple SL. Digital spectral analysis with applications. Prentice-Hall, Inc., Englewood Cliffs, New Jersey, 1987.

Neisser U, Boodoo G, Bouchard TJ, Boykin AW, Brody N, Ceci SJ, Halpern DF, Loehlin JC, Perloff R, Stenberg RJ, Urbina S. Intelligence: knows and unknowns. American Psychologist. 1996; 51:77-101. http://dx.doi. org/10.1037/0003-066X.51.2.77

Neubauer AC, Fink A, Schrausser DG. Intelligence and neural efficiency: the influence of task content and sex on the brain-IQ relationship. Intelligence. 2002; 30:515-36. http://dx.doi.org/10.1016/S0160-2896(02)00091-0

Neubauer AC, Fink A. Intelligence and neural efficiency. Neuroscience \& Biobehavioral Reviews. 2009; 33:1004-23. http://dx.doi.org/10.1016/j.neubiorev.2009.04.001

Pasquali L. Teste Não-Verbal de Raciocínio Infantil (TNVRI). São Paulo: Vetor Editora; 2005. Livro de Instruções.

Pfurtscheller G, Stancák Junior A, Neuper CH. Eventrelated synchronization(ERS) in the alpha band - an electrophysiological correlate of cortical idling: A review. International Journal of Psychophysiology. 1996; 24:39-46. http://dx.doi.org/10.1016/S0167-8760(96)00066-9

Shiavi R. Introduction to applied statistical signal analysis. 2th ed. San Diego: Academic Press; 1999.

Strenze T. Intelligence and socioeconomic success: A meta-analytic review of longitudinal research. Intelligence. 2007; 35:401-26. http://dx.doi.org/10.1016/j. intell.2006.09.004

Tierra-Criollo CJ. Monitorização objetiva da resposta à estimulação somato-sensitiva utilizando parâmetros espectrais [tese]. Rio de Janeiro: Universidade Federal do Rio de Janeiro; 2001.

Wechsler D. WISC-III: Escala de Inteligência Wechsler para crianças: Manual. 3th ed. São Paulo: Casa do Psicólogo; 2002.

\section{Authors}

\section{Marcela Mansur-Alves}

Laboratório de Avaliação das Diferenças Individuais, Departamento de Psicologia, Gab. 4008, Faculdade de Filosofia e Ciências Humanas, Universidade Federal de Minas Gerais - UFMG, Av. Antonio Carlos, 6627, CEP 31330-030, Belo Horizonte, MG, Brazil

\section{Carmen Flores-Mendoza}

Departamento de Psicologia, Faculdade de Filosofia e Ciências Humanas, Gab. 4042,

Universidade Federal de Minas Gerais - UFMG, Av. Antonio Carlos, 6627, CEP 31330-030, Belo Horizonte, MG, Brazil

\section{Sady Antonio dos Santos Filho}

Departamento de Engenharia Elétrica, Pontifícia Universidade Católica de Minas Gerais - PUC-Minas, Belo Horizonte, MG, Brazil

\section{Carlos Julio Tierra-Criollo}

Núcleo de Estudos de Engenharia Biomédica - NEPEB, Departamento de Engenharia Elétrica, Faculdade de Engenharia, Universidade Federal de Minas Gerais - UFMG, Av. Antonio Carlos, 6627, CEP 31330-030, Belo Horizonte, MG, Brazil 